\title{
Mannose Modified Co-Loaded Zoledronic Liposomes Deplete M2-tumor-associated Macrophages to Enhance Anti-Tumor Effect of Doxorubicin on TNBC
}

\section{Wendong Yao}

The First Affiliated Hospital of Zhejiang Chinese Medical University

\section{Hengwu Xu}

Jinhua People's Hospital

\section{Yanhong Chen}

Laboratory Animal Center of Zhejiang University

\section{Yingying $\mathrm{Xu}$}

Affiliated Hangzhou Chest Hospital

\section{Feng Zhou}

Affiliated Hangzhou Chest Hospital

\section{Zeng Wang}

Cancer Hospital of the University of Chinese Academy of Science

Xinjun Cai ( $\square$ zjtcmcxj@zcmu.edu.cn )

Affiliated Hangzhou Chest Hospital https://orcid.org/0000-0003-3606-8819

\section{Research Article}

Keywords: zoledronic acid, doxorubicin, M2-TAMs, mannose modified liposomes, TNBC

Posted Date: October 18th, 2021

DOl: https://doi.org/10.21203/rs.3.rs-904330/v1

License: (c) (1) This work is licensed under a Creative Commons Attribution 4.0 International License. Read Full License 


\section{Abstract}

As the most numerous inflammatory cell group in tumor microenvironment, tumor-associated macrophages (TAMs) have an essential effect in tumor therapy and are potential therapeutic targets. M2 type tumor-associated macrophages (M2-TAMs) were involved in the entire process of tumor development, invasion, and metastasis, obstructing the anti-tumor effect of chemotherapy drugs and nano-medicine. This study aimed to construct a mannose modified co-loaded zoledronic acid and doxorubicin liposomes (Man-LP@ZOL/DOX) for improving the anti-tumor effect by suppressing M2TAMs on triple-negative breast cancer (TNBC). The size, PDI, and Zeta-potential of Man-LP@ZOL/DOX liposomes were determined to be $212.80 \pm 7.74 \mathrm{~nm}, 0.1413 \pm 0.0232,-33.63 \pm 0.49 \mathrm{mV}$, respectively. The Man-LP@ZOL/DOX's EE\% and DL\% of ZOL as measured were $17.21 \pm 2.26 \%$ and $1.56 \pm 0.21 \%$, while for DOX, they were $84.42 \pm 2.05 \%$ and $5.12 \pm 0.14 \%$. The uptake of Man-LP into cells was increased when it was modified with a TAMs target ligand. The liposomes inhibited the invasion of MDA-MB-231 cells induced by M2-TAMs, and expression of biomarkers on M2-TAMs (Arg1 and CD206 in vitro, CD68, and CD206 in vivo) was apparent. Moreover, co-loaded drugs liposome system remarkably enhanced anticancer effects both in vitro and vivo combined with ZOL. In conclusion, all these results established that Man-LP@ZOL/DOX could enhance anti-tumor effect of DOX via depleting M2-TAMs on TNBC.

\section{Introduction}

Breast cancer is the most common female cancer worldwide [1-3]. Triple-negative breast cancer (TNBC) is the most aggressive breast cancer subtype, which is negative for estrogen receptor, progesterone receptor, and human epidermal growth factor receptor expressions, accounting for $15-20 \%$ of all breast cancer cases [1]. TNBC patients are non-responsive to therapies that target HER2 receptors or hormonal therapies due to their triple-negative status [2]. Adjuvant chemotherapy is the only systemic therapy available to TNBC patients [3]. Doxorubicin (DOX) is a commonly used anthracycline anti-tumor drug in clinical practice for treating breast cancer [4]. However, due to its high toxicity, prolonged use may result in dose-dependent irreversible cardiomyopathy, bone marrow suppression, alopecia, gastrointestinal symptoms, etc., and its multidrug resistance further limits its clinical application [5]. Nanotechnology, particularly nanoparticle and liposome-based drug delivery systems, can improve pharmacokinetics, targeted delivery, and reduced toxicity [6]. At present, Doxil/Caelyx liposomes (Doxil $\circledast /$ Caelyx $®$ ) have been translated into clinical applications [7]. Although the toxicity is reduced, its anti-tumor effect has not increased significantly.

Recent research has revealed that tumor microenvironment (TME) is an important reason for this phenomenon [8]. Tumor-associated macrophages (TAMs), as the most numerous inflammatory cell group in TME, have an essential effect in tumor therapy and are potential therapeutic targets [9]. TAMs mainly exist around tumor blood vessels, avascular areas, and hypoxic areas and could be divided into M1 and M2 types according to their activation state and function [10]. M1 type TAMs (M1-TAMs) highly express IL-1 and IL-6 and other cytokines [11], assisting anti-tumor function. M2 type TAMs (M2-TAMs) are required for tumor invasion, metastasis, immunosuppression, and neovascularization [12, 13]. M2- 
TAMs are not only the main components of monocyte population invading solid tumors but also promote tumor growth and development by producing anti-inflammatory cytokines such as IL-10 and TGF- $\beta$. Clinical samples testing revealed that M2-TAMs are abundant in many cancers including TNBC, which are important factors that cause drug resistance, metastasis, and invasion of these tumors [14]. Therefore, inhibiting the function of M2-TAMs and reducing their number is an effective measure to improve the anti-tumor effect of DOX-loading liposomes [15].

Clinically, bisphosphonates have proven safe and efficacious in managing bone resorptive diseases such as Paget's disease, osteoporosis, and meta-static bone disease [16]. As a third-generation bisphosphonate, zoledronic acid (ZOL) inhibits and reduces M2-TAMs [17] but does not affect M1-TAMs [18], which would be beneficial for TME improvement. However, ZOL is rapidly metabolized in vivo and cannot effectively reach tumor tissues. As a result, it is necessary to improve its tumor distribution [19]. To address the aforementioned issues, we previously loaded ZOL into liposomes and demonstrated tumor targeting effects [20]. In this study, based on our previous work, we designed a liposome-drug delivery system that co-loads anti-tumor drugs (DOX) and M2-TAMs inhibitors (ZOL) to achieve precise tumor-targeted therapy and enhance anti-tumor effect. Targeted drug delivery systems rely on ligands or antibodies to selectively enrich drugs in tumor sites and reduce drug concentration in normal tissue [21, 22]. Due to its high efficiency and low toxicity of drug delivery, it has become an effective strategy for tumor treatment [23]. Mannose receptor is a specific receptor found on the cell membrane surface of TAMs, which could recognize and bind endogenous and exogenous ligands [24]. Hence, altering the liposome surface with mannose (Man) may enable tumor-targeted delivery [25].

In summary, this study developed Man modified co-loaded ZOL and DOX liposomes (Man-LP@ZOL/DOX, Fig. 1) to enhance the anti-tumor effect, affecting tumor cells and M2-TAMs, respectively. We characterized liposomes in terms of their size distribution, Zeta potential, and morphology. Following that, encapsulation efficiency and drug loading of Man-LP@ZOL/DOX were appraised. Subsequently, we evaluated cellular uptake, cytotoxicity, and effect to invasion and expression of biomarkers of ManLP@ZOL/DOX. Finally, we conducted in vivo anti-tumor and immunohistochemistry studies.

\section{Materials And Methods}

\subsection{Materials}

ZOL was purchased from CTTO Medicine Co., Ltd. (Nanjing, China). Mannosamine-palmitic acid was obtained from Nayuansu Biological Technology Co., Ltd. (Shanghai, China). DOX was purchased from Macklin Co., Ltd. (Shanghai, China). Soyabean phosphatidylcholine (SPC) was supplied by Lipoid GmbH (Ludwigshafen, Germany). Distearoyl phosphoethanolamine-PEG2000 (DSPE-PEG-2000) and cholesterol were purchased from A.V.T Pharmaceutical Co., Ltd. (Shanghai, China). RPMI Medium Modified, Penicillin-Streptomycin Solution, and Phosphate Buffered Saline (1X) were obtained from HyClone (USA). FITC Mouse IgG2b k Isotype Control, FITC MOUSE Anti-Human (CD68), PE Mouse Anti-Human MSR1 (CD204), PE-Cy 5 conjugated mouse/primate immunoglobulin G1 K chain antibody, PE-Cy 5 conjugated 
Anti-Human (CD206), and PE Mouse IgG1 $\mathrm{k}$ Isotype Control RUO were purchased from BD BIOSCIENCES (San Diego, USA). Anti-GAPDH antibody, Anti-Mannose Receptor antibody, and Anti-Liver Arginase antibody were purchased from Abcam (Cambridge, UK). Dulbecco's modified Eagle medium (DMEM), fetal bovine serum (FBS), 3-(4,5-Dimethylthiazol-2-yl)-2,5-diphenyltetrazolium bromide (MTT), penicillin G sodium, and streptomycin sulfate were obtained from Gibco BRL (Gaithersburg, USA). Other chemicals and solvents were all of analytical grade, and purified water was produced by a Millipore water purification system.

\subsection{Cell culture and animals}

Human mononuclear macrophages (THP-1) and human triple-negative breast cancer cell line (MDA-MB231) were purchased from Type Culture Collection of the Chinese Academy of Sciences, Shanghai, China.

Four to six-week-old female BALB/c nude mice weighing 16-18 g were purchased from Zhejiang University Animal Laboratory (Hangzhou, China). The animals were housed in cages and had free access to tap water and standard laboratory food throughout experiments.

\subsection{Preparation of LP and Man-LP}

The ethanol injection method was used to prepare blank liposome (LP), and Man modified liposome (Man-LP) [26]. First, $200 \mathrm{mg}$ of soy lecithin, $60 \mathrm{mg}$ of cholesterol, $45 \mathrm{mg}$ of DSPE-PEG2000, and $4.00 \mathrm{mg}$ of mannosamine-palmitic acid were dissolved in ethanol and stirred in a water bath at $65^{\circ} \mathrm{C}$. Following that, they were injected into water at a rate of $0.5 \mathrm{~mL} / \mathrm{s}$ and stirred at $65^{\circ} \mathrm{C}$ for $20 \mathrm{~min}$. After sonication for $8 \mathrm{~min}(200 \mathrm{~W} \times 2 \mathrm{~min}, 400 \mathrm{~W} \times 6 \mathrm{~min})$, the initially formed liposome was passed through microporous membranes of $0.80,0.45$, and $0.22 \mu \mathrm{m}$ to obtain Man-LP. LP was prepared in the same manner without mannosamine-palmitic acid.

\subsection{Preparation of LP@ZOL/DOX, Man-LP@ZOL, and Man- LP@ZOL/DOX}

Based on ethanol injection method, DOX was actively encapsulated by ammonium gradient method to realize co-loading of the two drugs in liposomes. First, $600 \mathrm{mg} \mathrm{ZOL}$ was added to $2 \mathrm{~mL}$ of water and stirred until dispersion. Following that, $275 \mu \mathrm{L}$ of ammonia water with a concentration of $14.9 \mathrm{~mol} / \mathrm{L}$ was slowly added dropwise to completely dissolve ZOL. The resultant solution was dissolved to $10 \mathrm{~mL}$ to obtain $\left(\mathrm{NH}_{4}\right)_{2} \mathrm{Zol}$ solution. A mixed solution of $0.5 \mathrm{~mL}$ of $\left(\mathrm{NH}_{4}\right)_{2} \mathrm{ZOL}$ solution and $9.5 \mathrm{~mL}$ of $0.2 \mathrm{~mol} / \mathrm{L}$ $\left(\mathrm{NH}_{4}\right)_{2} \mathrm{SO}_{4}$ solution was stirred as a hydration medium for liposome preparation, followed by heating at $65^{\circ} \mathrm{C}$ water baths. Subsequently, $200 \mathrm{mg}$ of soy lecithin, $60 \mathrm{mg}$ of cholesterol, $45 \mathrm{mg}$ of DSPE-PEG2000, and $4.00 \mathrm{mg}$ of mannosamine-palmitic acid were dissolved in ethanol and stirred at $65^{\circ} \mathrm{C}$. Then, they were injected into the hydration medium or $\left(\mathrm{NH}_{4}\right)_{2} \mathrm{Zol}$ solution at a rate of $0.5 \mathrm{~mL} / \mathrm{s}$ and stirred at $65^{\circ} \mathrm{C}$ for $20 \mathrm{~min}$. After sonication for $8 \mathrm{~min}(200 \mathrm{~W} \times 2 \mathrm{~min}, 400 \mathrm{~W} \times 6 \mathrm{~min})$, the product passed through microporous membranes of $0.80,0.45$, and $0.22 \mu \mathrm{m}$ to obtain Man modified ZOL liposome (ManLP@ZOL).Man-LP@ZOL and $5.0 \mathrm{mg} / \mathrm{mL}$ doxorubicin solution were mixed according to the weight ratio of 1:10 and incubated at $60^{\circ} \mathrm{C}$ with stirring. After $20 \mathrm{~min}$, they were taken out and placed at room 
temperature to terminate drug loading. Finally, Man-LP@ZOL/DOX was purified using centrifugation. LP@ZOL/DOX was prepared in the same manner without mannosamine-palmitic acid.

\subsection{Characterization}

The size distribution, polydispersity index (PDI), and Zeta-potential of liposomes were measured using Malvern ZEN 3690. Transmission electron microscopy (TEM) image of Man-LP@ZOL/DOX was obtained using a transmission electron microscope (H-7650, Hitachi, Japan), using $2 \%$ phosphotungstic acid solution negative staining [27].

Encapsulation efficiency (EE\%) and drug loading (DL\%) were determined according to a previously reported method. Briefly, $1 \mathrm{~mL}$ of liposome dispersions was eluted with PBS (pH 7.4) through Sephadex G-100 column to remove unloaded ZOL. The entrapped ZOL was determined by disrupting liposome dispersions with ethanol (the ratio of volume of methanol to liposome was $5: 1$ ). ZOL in liposome was measured using high-performance liquid chromatography (HPLC). After that, $1 \mathrm{~mL}$ of liposome was demulsified by $90 \%$ isopropanol (containing $0.75 \mathrm{~mol} / \mathrm{L} \mathrm{HCl}$ ) and diluted to $10 \mathrm{~mL}$. The absorbance of DOX in liposome was measured at $480 \mathrm{~nm}$ wavelength, and drug concentration was calculated. The encapsulation efficiency and drug loading of ZOL and DOX were estimated by Eqs. (1) and (2) $[27,28]$.

\section{$E E \%=\left(W_{\text {drug }} / W_{\text {total }}\right) \times 100 \%(1)$ \\ $D L \%=\left(W_{\text {drug }} / W_{\text {LP }}\right) \times 100 \%(2)$}

$W_{\text {drug }}$ is the measured amount of drug (ZOL or DOX) in the liposome suspension; $W_{\text {total }}$ is the weight of $\mathrm{ZOL}$ or DOX in the equal volume of liposome suspensions; $\mathrm{W}_{\text {drug }}$ is the measured weight of liposome lyophilized powder.

\subsection{Induction and identification of M2-TAMs}

THP-1 cells were cultured in a 1640 complete medium containing $0.05 \mathrm{mM} \beta$-mercaptoethanol at $37{ }^{\circ} \mathrm{C}$ in $5 \% \mathrm{CO}_{2}$ incubator. THP-1 cell concentration was adjusted to $1 \times 10^{6}$ cells $/ \mathrm{mL}$ with $\mathrm{M} \varphi$-type cell induction solution composed of serum-free 1640 medium, $100 \mathrm{ng} / \mathrm{mL}$ PMA, and $0.3 \%$ BSA. After $48 \mathrm{~h}$ of being cultured, non-adherent cells were centrifuged. Then, the cells were cultured with adherent cells in the original flask with $M \varphi$-type cell induction solution. The cells were observed, and $M \varphi$-type cell induction medium was repeatedly replaced every $48 \mathrm{~h}$. After 14 days of induction, the cells (suspended and adherent cells) were cultured with $\mathrm{M} 2$ cell induction solution composed of serum-free 1640 medium and $20 \mathrm{ng} / \mathrm{mL} \mathrm{IL}-4$. After $48 \mathrm{~h}$ of induction, the cell culture medium was replaced with 1640 complete medium. After 48 h, M2-TAMs cells were collected and randomly divided into CD68, CD206, CD204 groups [29]. A total of $3 \mu \mathrm{L}$ CD68 antibodies were added to the CD68 group, $10 \mu \mathrm{L}$ CD206 antibodies were added to the CD206 group, and $10 \mu \mathrm{L}$ CD204 antibodies were added to the CD204 group. After incubating for 30 min, the cells were washed twice with PBS to remove unbound antibodies and were detected using a flow cytometer (Accuri C6, BD, USA).

\subsection{Cellular uptake and intracellular disposition}


M2-TAMs in logarithmic growth phase were seeded in 6-well plates at $5 \times 10^{5}$ cells/well in $5 \% \mathrm{CO}_{2}$ at $37{ }^{\circ} \mathrm{C}$ for $24 \mathrm{~h}$. After that, cells were treated with FITC-labeled LP and FITC-labeled Man-LP ( $3 \mu \mathrm{mol} / \mathrm{L} \mathrm{FITC})$ or blank serum-free culture medium at $37^{\circ} \mathrm{C}$. After $1 \mathrm{~h}$, cells were washed three times with PBS, then trypsinized and collected by centrifugation. The mean fluorescence intensity (MFI) was determined using a flow cytometer (Accuri C6, BD, USA). Next, confocal laser scanning microscopy (CLSM, Zeiss LSM880, Carl Zeiss, Germany) was applied to identify intracellular localization of FITC-labeled liposomes in cells.

M2-TAMs cells were incubated in sterile glass-bottom dishes at a density of $1 \times 10^{5}$ cells/well and cultured in $5 \% \mathrm{CO}_{2}$ at $37^{\circ} \mathrm{C}$ for $12 \mathrm{~h}$. Following that, cells were treated for $4 \mathrm{~h}$ with a culture medium containing FITC-labeled LP or FITC-labeled Man-LP at a FITC concentration of $3 \mu \mathrm{mol} / \mathrm{L}$. After three washes with PBS, the cells were stained with Hoechst 33342 and fixed with $4 \%(\mathrm{v} / \mathrm{v})$ paraformaldehyde. The sterile glass dish was placed under CLSM to observe the fluorescence signal.

\subsection{In vitro cytotoxicity}

The MTT assay was utilized to evaluate the cytotoxicity of drug-free carriers and drug loading liposomes on MDA-MB-231 cells. Briefly, the cells were seeded in 96 -well plates at a density of $8 \times 10^{3}$ cells/well, and cultured overnight at $37^{\circ} \mathrm{C}$. The cells were then treated with a serum-free culture medium containing drug-free carriers or drug loading liposomes at different concentrations for $48 \mathrm{~h}$. The cells were incubated with a culture medium mixed with MTT $(5 \mathrm{mg} / \mathrm{mL})$ for $4 \mathrm{~h}$. After discarding the supernatant, precipitates were dissolved in $150 \mathrm{~mL}$ DMSO, and the absorbance of the resulting solution was measured at a wavelength of $570 \mathrm{~nm}$ using a microplate reader (Synergy TM2, BIO-TEK Instruments Inc. USA) [30].

\subsection{Effect to invasion}

The transwell method was used to detect the effect of Man-LP, ZOL, and Man-LP@ZOL on MDA-MB-231 cell invasion. First, the matrigel and serum-free medium were mixed at a ratio of 1:3. They were spread evenly to the bottom of transwell inserts (Corning, USA) and incubated overnight at $37^{\circ} \mathrm{C}$. Next, MDA-MB231 cells were seeded into transwell inserts at a density of $1 \times 10^{5}$ cells/well, while M2-TAMs were seeded into transwell plates at a density of $2 \times 10^{5}$ cells/well, constructing a non-contact co-cultivation system. The transwell plate of control group was not seeded with M2-TAMs. The cells were then cultured in a serum-free culture medium containing Man-LP, ZOL, Man-LP@ZOL, or an equal amount of PBS. The control group was cultured in a serum-free medium. After $24 \mathrm{~h}$, matrigel and MDA-MB-231 cells at the inner of transwell inserts were wiped. The cells passed through transwell inserts were fixed with $4 \%$ paraformaldehyde for $10 \mathrm{~min}$ and then stained with $0.1 \%$ crystal violet solution for $30 \mathrm{~min}$. The stained cells were taken pictures of cells that have invaded the lower layer [31].

\subsection{Effect to expression of Arg1 and CD206}

M2-TAMs cells in the logarithmic growth phase were seeded in plates in $5 \% \mathrm{CO}_{2}$ at $37{ }^{\circ} \mathrm{C}$ for $24 \mathrm{~h}$. The cells were then cultured in a serum-free medium supplemented with Man-LP, ZOL, Man-LP@ZOL, or PBS. After $48 \mathrm{~h}$, the cells were harvested and lysed in RIPA buffer with protease inhibitors (PMSF). BCA kit (Solarbio Cat, China) was used for quantitative analysis of protein. Equal amounts of total proteins were 
separated in a polyacrylamide gel containing $5 \%$ sodium dodecyl sulfate and transferred to a polyvinylidene fluoride membrane (GE Healthcare Life, USA). Next, the membranes were blocked in $5 \%$ nonfat powder and incubated with primary antibodies (Anti-GAPDH, Anti-Arg1, Anti-CD206) at $4{ }^{\circ} \mathrm{C}$ overnight. After washing with TBS containing $0.1 \%$ Tween 20 , the membranes were incubated with secondary antibodies for $2 \mathrm{~h}$ at room temperature. After the reaction, the membranes were washed three times with TBS containing $0.1 \%$ Tween 20 . The protein bands were visualized using ECL Chemiluminescence Analyzer (Clinx Science Instruments, Shanghai) [32, 33].

\subsection{In vivo anti-tumor study}

In vivo anti-tumor study was conducted on breast cancer tumor xenograft mice established by subcutaneously injecting MDA-MB-231 and M2-TAMs cells into BALB6 female mice. When the tumor grows to $80 \mathrm{~mm}^{3}$, the tumor xenograft mice were randomly divided into PBS group (control group), ZOL + DOX group, LP@ZOL/DOX group, and Man-LP@ZOL/DOX group. Man-LP@ZOL/DOX at a dose of 3 mg DOX-equivalent $/ \mathrm{kg}$ and $0.3 \mathrm{mg}$ ZOL-equivalent $/ \mathrm{kg}$ body weight (or PBS) was intravenously administrated daily. Body weight and tumor size were recorded at 1, 4, 7, 9, 11, and 14 days. Six mice of each group were killed on day 14 , and tumor tissues were collected and weighted. The tumor volumes and tumor growth inhibition rate (IR\%) were calculated by Eqs. (3) and (4) [34].

$V=\left(a \times b^{2}\right) / 2(3)$

$\mathrm{IR} \%=\left(1-\mathrm{W}_{\text {Tre }} / \mathrm{W}_{\text {Con }}\right) \times 100 \%(4)$

Regarding the formulas, $\mathbf{a}, \mathrm{b}, \mathrm{W}_{\mathrm{Tre}}$ and $\mathrm{W}_{\text {con }}$ refer to the maximum diameter of tumor, the minimum diameter of tumor, the mean tumor weight of treated groups, and the mean tumor weight of the control group, respectively.

\subsection{Immunohistochemistry Staining}

After the in vivo anti-tumor study, the removed tumors were sectioned for pathological analysis. Paraffinembedded tumor tissue sections were histochemically stained with hematoxylin or immunohistochemically stained with fluorescein-labeled antibodies (CD68 and CD206). Images were captured using a photomicroscope (ECLIPSE E100, Nikon, Japan), and assessment of intensity or cumulative optical density (IOD) was completed using Image-Pro Plus 6.0 software.

\section{Results And Discussion}

\subsection{Preparation and characterization}


Our previous study demonstrated that ZOL could affect tumor cells by inhibiting M2-TAMs [20]. Ottewell et al. found that when ZOL was administered $24 \mathrm{~h}$ post-treatment with DOX in MDA-MB-436 cells, this led to an increase in the expression of proapoptotic genes, while the presence of unprenylated Rap1 indicated induced apoptosis [35]. However, approximately $50 \%$ of bisphosphonates, including ZOL, is renaly excreted, and the remainder is mainly concentrated on the bone surface in vivo. This results in a low drug concentration at the tumor site. Based on previous research [20], Man-LP@ZOL/DOX was designed to achieve ZOL's tumor targeting and enhance anti-tumor effect of DOX.

In this study, the ethanol injection and ammonium gradient methods were combined to prepare ManLP@ZOL/DOX. The size, PDI, and Zeta-potential of Man-LP@ZOL/DOX were 212.80 7.74 nm, $0.1413 \pm$ $0.0232,-33.63 \pm 0.49 \mathrm{mV}$, respectively. TEM image (Fig. 2) displays that Man-LP@ZOL/DOX was spherical and dispersed favorably. Man-LP@ZOL/DOX's EE\% and DL\% of ZOL as measured were $17.21 \pm 2.26 \%$ and $1.56 \pm 0.21 \%$, while EE\% and DL\% of DOX were $84.42 \pm 2.05 \%$ and $5.12 \pm 0.14 \%$. The LP@ZOL/DOX's EE\% and DL\% of ZOL were $15.68 \pm 3.17 \%$ and $1.45 \pm 0.31 \%$, while EE\% and DL\% of DOX were $78.89 \pm$ $1.12 \%$ and $4.85 \pm 0.07 \%$. Liposomes have been used extensively to deliver hydrophilic cargos such as $\mathrm{ZOL}$, which are passively loaded in the aqueous core [36]. Because of the primary amino group, DOX was positively charged and actively loaded to the core of liposomes containing ZOL (negative charge). As a result, EE\% of ZOL in LP@ZOL/DOX and Man-LP@ZOL/DOX were lower than DOX.

\subsection{Induction and identification of M2-TAMs}

An important reason for unsatisfactory effect of chemotherapy was ignoring TME during treatment. M2TAMs were the most important non-tumor cells in TME, which play an indispensable role in tumor growth, invasion, angiogenesis, metastasis, and immunosuppression. More importantly, M2-TAMs in TNBC is associated with a higher risk of progression and distant metastasis [37]. Herein, M2-TAMs cells were induced and identified in vitro for verifying the effect of ZOL-loaded liposome. Moreover, CD68, CD204, and CD206 are biomarkers present on M2-TAMs. As presented in Fig. 3, three biomarkers of M2-TAMs were detected and exhibited significantly increased expression of CD68, CD206, and CD204 $(P<0.01)$. The result indicates that M2-TAMs were successfully induced.

\subsection{Cellular uptake and intracellular disposition}

To estimate cellular uptake of FITC-labeled LP and Man-LP, flow cytometry analysis was implemented by M2-TAMs. As illustrated in Fig. 4A-B, the mean fluorescence intensity (MFI) of FITC-labeled LP and ManLP groups were increased significantly compared with the control group $(P<0.01)$. It demonstrates that

M2-TAMs could internalize FITC-labeled LP and Man-LP. MFI of FITC-labeled Man-LP group was 1.24-fold higher than FITC-labeled LP group. The results indicated that Man ligand could specially recognize mannose receptor on surfaces of M2-TAMs and achieve targeted drug delivery.

To determine subcellular localization of FITC-labeled LP and Man-LP, CLSM was used to observe M2TAMs after incubation for $4 \mathrm{~h}$ with culture medium containing FITC-labeled LP or FITC-labeled Man-LP at 
a FITC concentration of $3 \mu \mathrm{mol} / \mathrm{L}$. As depicted in Fig. 4C, fluorescence signals were chiefly localized in cytoplasm, indicating that FITC-labeled liposomes were internalized by endocytosis. A stronger FITC fluorescence signal could be observed from FITC-labeled Man-LP compared to that of FITC-labeled LP. This finding was consistent with flow cytometry analysis data.

\subsection{In vitro cytotoxicity}

To evaluate biocompatibility of LP and Man-LP, drug-free liposomes were incubated with MDA-MB-231 cells. Over $85 \%$ of all cells remained viable during incubation with LP and Man-LP at a concentration below $0.80 \mathrm{mg} / \mathrm{mL}$ (Fig. 5A). The results indicated that LP and Man-LP exhibited intrinsically low toxicity and good biocompatibility at common concentrations. However, LP and Man-LP both indicated inhibition of cells at high concentrations [30].

To appraise cytotoxicity of drug loading liposomes compared with original drugs (ZOL + DOX), cells were exposed to ZOL + DOX, LP@ZOL/DOX, and Man-LP@ZOL/DOX for 48 h. The viability of cells was inhibited with increasing drug concentrations among the groups (Fig. 5B). The half-maximal inhibitory concentration (IC50) values of ZOL + DOX, LP@ZOL/DOX, and Man-LP@ZOL/DOX were 290.10 19.21 $\mathrm{ng} / \mathrm{mL}, 190.83 \pm 13.78 \mathrm{ng} / \mathrm{mL}$, and $144.01 \pm 10.15 \mathrm{ng} / \mathrm{mL}$, respectively. It can be inferred that drug's toxicity to cells increases following liposome loading. The reason for this phenomenon might be that lipid bilayer played an important role in increasing inherent affinity between liposomes and cell membrane, therefore promoting cellular uptake through a mechanism described as contact-facilitated drug delivery. The higher cytotoxicity of Man-LP@ZOL/DOX to cells, compared with LP@ZOL/DOX, may cause a higher intracellular concentration of drugs that was improved via mannose receptor-mediated endocytosis. It is worth noting that MDA-MB-231 cells maintained a high level of survival rate at IC50 value cells induced by Man-LP@ZOL/DOX. Hence, Man-LP@ZOL/DOX was favorable for treating TNBC with limited side effects and enhanced anticancer effects.

\subsection{Effect on invasion}

To evaluate the effect of ZOL and ZOL-loaded liposomes on cell invasion, the transwell method was adopted on MDA-MB-231 cells induced by M2-TAMs. As presented in Fig. 6, the number of invaded MDAMB-231 cells increased in PBS and Man-LP groups $(P<0.05)$ compared with the control group without M2-TAMs. This indicates that M2-TAMs' induction or secreted characteristic cytokines magnify tumor cell invasion. Besides, the blank liposome does not affect cell invasion. Compared with the control group, the number of invaded MDA-MB-231 cells in Man-LP@ZOL and ZOL groups was significantly reduced (P < 0.01). This indicates that ZOL could effectively inhibit MDA-MB-231 cell invasion. Additionally, inhibiting ZOL binding to M2-TAMs weakened the invasion ability of MDA-MB-231 cells. In addition, compared with ZOL group, Man-LP@ZOL group had a more apparent inhibitory effect on the invasion of MDA-MB-231 cells $(P<0.01)$. This could be due to the increased intracellular concentration of ZOL improved by ManLP.

\subsection{Effect on expression of Arg1 and CD206}


CD206 is a biomarker present on M2-TAMs [38]. However, M2-TAMs secrete characteristic phenotypic molecules, such as Arg1, Fizz1, and Msr2. This study applied the western blot method to quantify M2TAMs' expression of Arg1 and CD206 treated with Man-LP, ZOL, and Man-LP@ZOL. According to Fig. 7, no significant difference was observed in Arg1 and CD206 expressions in M2-TAMs cells of Man-LP group compared with control group, which was treated with a serum-free culture medium containing equal amount of PBS. In contrast, Arg1 and CD206 expressions in M2-TAMs cells of ZOL $(P<0.05)$ and Man-LP@ZOL groups $(P<0.01)$ were significantly reduced. Enhanced targeting capabilities via Man-LP allow more ZOL to enter cells. Subsequently, we could infer that M2-TAMs and expressed proteins are inhibited by ZOL-loading liposomes.

\subsection{In vivo anti-tumor study}

Because of the promising effects observed in vitro, we continued to accomplish in vivo studies using TNBC bearing mice modeled by M2-TAMs and MDA-MB-231 cells. The tumor volume with time extension is illustrated in Fig. 8A-B after mice were treated with either PBS or ZOL + DOX, ZOL + DOX loading liposomes. On day 14, all drug preparations suppressed tumor growth compared with the control group $\left(718.89 \pm 129.66 \mathrm{~mm}^{3}, \mathrm{P}<0.01\right)$. Furthermore, we revealed that mean tumor volume of ManLP@ZOL/DOX group (205.28 $\pm 83.02 \mathrm{~mm}^{3}$ ) was significantly reduced compared with LP@ZOL/DOX group (318.62 $\left.\pm 49.75 \mathrm{~mm}^{3}, \mathrm{P}<0.05\right)$. As for tumor weight in Table 1, all three drug administration groups were lightened than the control group $(0.63 \pm 0.14 \mathrm{~g}, \mathrm{P}<0.01)$. Additionally, the mean tumor weight in Man-LP@ZOL/DOX group (0.18 $\pm 0.09 \mathrm{~g})$ was markedly reduced compared with LP@ZOL/DOX group $(0.28 \pm 0.10 \mathrm{~g}, \mathrm{P}<0.05)$. Accordingly, the tumor weight followed the same tendency as that of tumor volume. IR\% of Man-LP@ZOL/DOX group was 70.82\% higher than that of LP@ZOL/DOX (55.46\%) and ZOL + DOX groups (48.96\%). As a result, considering the remarkable efficacy of the two drugs in cells, the enhanced effect of drug loading liposomes principally resulted from targeted drug delivery. Man-

LP@ZOL/DOX, with improved targeting effect, exhibited the best inhibitory effect on tumor growth.

Table 1

Tumor weight and IR\% of each group after treating $(n=6)$.

\begin{tabular}{|lll|}
\hline Groups & Tumor weight (g) & IR(\%) \\
\hline Con & $0.63 \pm 0.14$ & $/$ \\
\hline ZOL + DOX & $0.32 \pm 0.14$ & 48.96 \\
\hline LP@ZOL/DOX & $0.28 \pm 0.10$ & 55.46 \\
\hline Man-LP@ZOL/DOX & $0.18 \pm 0.09$ & 70.82 \\
\hline
\end{tabular}

For safety evaluation, noticeable body weight loss is observed in Fig. $8 \mathrm{C}$ after drug administration compared with control group $(\mathrm{P}<0.01)$. Chemotherapy-induced weight loss is among the serious problems in cancer treatment [39]. This may have been caused by severe toxicity of DOX. The weight 
change (Weight change = final weight - initial weight) trend of LP@ZOL/DOX and Man-LP@ZOL/DOX groups slowed down after seven days compared with ZOL + DOX group, demonstrating a downward trend during administration period. Furthermore, weight changes of LP@ZOL/DOX and Man-LP@ZOL/DOX groups at day 14 were smaller than $Z O L+D O X$ group $(P<0.05)$. This indicates that liposome group has decreased toxicity to TNBC bearing mice compared to original drug, as the liposome reduced DOX exposure to normal tissue.

\subsection{Immunohistochemistry Staining}

Through the principle of specific antigen-antibody binding, a color reagent (fluorescein, enzyme, metal ion, and isotope) labeled antibody could be developed to determine the antigen (polypeptide and protein) in tissue cells for locating, qualitatively evaluating, and quantifying research [40]. As displayed in Fig. 9, IOD of CD68 and CD206 expression in control group was significantly higher than the other group treated with ZOL $(P<0.01)$. According to Fig. 9, IOD of CD68 in Man-LP@ZOL/DOX group was lower than DOX+ ZOL $(P<0.01)$ and LP@ZOL/DOX groups $(P<0.05)$. As demonstrated in Fig. 9, IOD of CD206 in ManLP@ZOL/DOX group was found to be weaker than DOX + ZOL $(P<0.01)$ and LP@ZOL/DOX groups $(P<$ 0.01). The results revealed that Man-LP@ZOL/DOX conferred more ZOL exposure in TME by active targeting, causing a decrease in CD68 and CD206 expression.

Numerous clinical evidences had demonstrated that M2-TAMs were the principal cause of hypoxic environment in tumor tissues, the formation of tumor-related blood vessels and lymphatic vessels, immunosuppression, chemotherapy resistance and radiotherapy resistance, and the activation of tumor stem cells, which were involved in the entire process of tumor development, invasion and metastasis [41]. The number of M2-TAMs is directly related to poor prognosis of tumor patients [12,13]. Therefore, the construction of ZOL-loaded TAM targeting nanocarriers was an ingenious strategy, which could reduce the number of M2-TAMs in TME and even reshape phenotype of M2-TAMs, turning them from "accomplices" in promoting tumor growth to "guards" in killing tumors (M1-TAMs). In this study, we not only loaded ZOL into Man-modified liposomes to deplete M2-TAMs but also co-loaded DOX to strengthen anti-tumor effects in vitro and in vivo.

\section{Conclusion}

In this study, Man modified co-loaded ZOL and DOX liposomes were successfully designed and established as a tumor-targeting to affect tumor cells and M2-TAMs, respectively. Combined with ZOL, the co-loaded drug liposome system remarkably enhanced anticancer effects on TNBC both in vitro and in vivo via depleting M2-TAMs. Man, a non-toxic and pharmacological activity ligand, was innovatively modified on the liposome surface to increase DDS and cell membrane affinity for targeting delivery. In summary, our study provided additional evidence that Man-LP@ZOL/DOX could improve the anticancer effect of DOX via depleting M2-TAMs.

\section{Ethical Statement:}




\section{Declarations}

\section{Ethics approval and consent to participate}

All animal-related procedures and their care were conducted following institutional and governmental guidelines of Zhejiang Province.

\section{Consent for publication}

All the authors agree to the release of the copyright to the publisher when the manuscript is accepted for publication.

\section{Availability of data and materials}

The datasets used or analysed during the current study are available from the corresponding author on reasonable request.

\section{Competing interests}

The authors declare no conflicts of interest.

\section{Funding}

This study was financially supported by the Joint Funds of the Zhejiang Provincial Natural Science Foundation of China (No. LYY18H300001), the National Natural Science Foundation of China (No. 82003669), Zhejiang Medical and Health Science and Technology Plan (No. 2020KY741, 2020KY477), Zhejiang Traditional Chinese Medicine Scientific Research Fund Project (No. 2021ZB213), Medical promising youngster of Hangzhou, Talent Training Program of Zhejiang Cancer Hospital, Hangzhou Health Science and Technology Plan Project (No. 2017A35), and Jinhua Science and Technology Research Plan Project (No. 2021-3-116, 2019-4-037).

\section{Authors' contributions}

Yao Wendong: Main Experimenter, Writing-Original Draft.

Xu Hengwu: Main Experimenter, Data Visualization.

Chen Yanhong: Validation, Data Visualization.

Xu Yingying: Supervision,Data Curation.

Zhou Feng: Supervision, Data Curation.

Wang Zeng: Writing; Review \& Editing.

Cai Xinjun: The Designer of drug delivery system, Writing; Review \& Editing. 


\section{Acknowledgments}

The authors would like to acknowledge the support from Affiliated Hangzhou Chest Hospital, Zhejiang University School of Medicine and the First Affiliated Hospital of Zhejiang Chinese Medical University.

\section{References}

1. Blackley E, Loi S. Targeting immune pathways in breast cancer: review of the prognostic utility of TILs in early stage triple negative breast cancer (TNBC). Breast (Edinburgh, Scotland). 2019:S44-S8.

2. Dong H, Claffey K, Brocke S, Epstein P. Inhibition of breast cancer cell migration by activation of cAMP signaling. Breast cancer research treatment. 2015;152(1):17-28.

3. Li Y, Zhou Y, Mao F, Lin Y, Zhang X, Shen S. et al. Adjuvant addition of capecitabine to early-stage triple-negative breast cancer patients receiving standard chemotherapy: a meta-analysis. Breast cancer research treatment. 2020;179(3):533 - 42.

4. Chang A, Wu Q, Jenkins I, Specht J, Gadi V, Gralow J. et al. Phase I/II Trial of Combined Pegylated Liposomal Doxorubicin and Cyclophosphamide in Metastatic Breast Cancer. Clin Breast Cancer. 2018;18(1):e143-e9.

5. Tang J, Zhang L, Gao H, Liu Y, Zhang Q, Ran R. et al. Co-delivery of doxorubicin and P-gp inhibitor by a reduction-sensitive liposome to overcome multidrug resistance, enhance anti-tumor efficiency and reduce toxicity. Drug Deliv. 2016;23(4):1130-43.

6. Patel N, Pattni B, Abouzeid A, Torchilin V. Nanopreparations to overcome multidrug resistance in cancer. Adv Drug Deliv Rev. 2013;65:1748-62.

7. Milosevits G, Rozsnyay Z, Kozma G, Milosevits J, Tömöry G, Robotka H. et al. Flow cytometric analysis of supravesicular structures in doxorubicin-containing pegylated liposomes. Chem Phys Lipids. 2012;165(4):482-7.

8. Reichel D, Tripathi M, Perez J. Biological Effects of Nanoparticles on Macrophage Polarization in the Tumor Microenvironment. Nanotheranostics. 2019;3(1):66-88.

9. Carbó J, León T, Font-Díaz J. De la Rosa J, Castrillo A, Picard F, et al. Pharmacologic Activation of LXR Alters the Expression Profile of Tumor-Associated Macrophages and the Abundance of Regulatory T Cells in the Tumor Microenvironment. Cancer research. 2021;81(4):968 - 85.

10. Landry A, Balas M, Alli S, Spears J, Zador Z. Distinct regional ontogeny and activation of tumor associated macrophages in human glioblastoma. Scientific reports. 2020;10(1):19542.

11. McClellan J, Davis J, Steiner J, Enos R, Jung S, Carson J. et al. Linking tumor-associated macrophages, inflammation, and intestinal tumorigenesis: role of MCP-1. American journal of physiology Gastrointestinal liver physiology. 2012;303(10):G1087-95.

12. Vinnakota K, Zhang Y, Selvanesan B, Topi G, Salim T, Sand-Dejmek J. et al. M2-like macrophages induce colon cancer cell invasion via matrix metalloproteinases. Journal of cellular physiology. 2017;232(12):3468-80. 
13. Ye X, An L, Wang X, Zhang C, Huang W, Sun C. et al. ALOX5AP Predicts Poor Prognosis by Enhancing M2 Macrophages Polarization and Immunosuppression in Serous Ovarian Cancer Microenvironment. Frontiers in oncology. 2021;11:675104.

14. Mia S, Warnecke A, Zhang X, Malmström V, Harris R. An optimized protocol for human M2 macrophages using M-CSF and IL-4/IL-10/TGF- $\beta$ yields a dominant immunosuppressive phenotype. Scand J Immunol. 2014;79(5):305 - 14.

15. Zeng Z, Liu Y, Wen Q, Li Y, Yu J, Xu Q. et al. Experimental study on preparation and anti-tumor efficiency of nanoparticles targeting M2 macrophages. Drug Deliv. 2021;28(1):943 - 56.

16. Roelofs A, Thompson K, Ebetino F, Rogers M, Coxon F. Bisphosphonates: molecular mechanisms of action and effects on bone cells, monocytes and macrophages. Curr Pharm Design. 2010;16(27):2950-60.

17. Lv J, Chen F, Liu C, Liu P, Feng Z, Jia L. et al. Zoledronic acid inhibits thyroid cancer stemness and metastasis by repressing M2-like tumor-associated macrophages induced Wnt/ $\beta$-catenin pathway. Life sciences. 2020;256:117925.

18. Fowler D, Copier J, Dalgleish A, Bodman-Smith M. Zoledronic acid renders human M1 and M2 macrophages susceptible to V $\delta 2 \gamma \delta \mathrm{T}$ cell cytotoxicity in a perforin-dependent manner. Cancer immunology immunotherapy: CII. 2017;66(9):1205-15.

19. Mönkkönen H, Ottewell P, Kuokkanen J, Mönkkönen J, Auriola S, Holen I. Zoledronic acid-induced IPP/Apppl production in vivo. Life sciences. 2007;81(13):1066-70.

20. Cai X-J, Fei W-D, Xu Y-Y, Xu H, Yang G-Y, Cao J-W. et al. Liposome-Encapsulated Zoledronate Favors Tumor Vascular Normalization and Enhances Anticancer Efficacy of Cisplatin. AAPS PharmSciTech; 2020.

21. Liang T, Zhang R, Liu X, Ding Q, Wu S, Li C. et al. Recent Advances in Macrophage-Mediated Drug Delivery Systems. Int J Nanomed. 2021;16:2703-14.

22. Raza A, Hayat $U$, Rasheed T, Bilal M, Iqbal H. Redox-responsive nano-carriers as tumor-targeted drug delivery systems. Eur J Med Chem. 2018;157:705 - 15.

23. Sanadgol N, Wackerlig J. Developments of Smart Drug-Delivery Systems Based on Magnetic Molecularly Imprinted Polymers for Targeted Cancer Therapy: A Short Review. Pharmaceutics. 2020;12(9).

24. Andersen M, Andersen N, Rødgaard-Hansen S, Hokland M, Abildgaard N, Møller H. The novel biomarker of alternative macrophage activation, soluble mannose receptor (sMR/sCD206): Implications in multiple myeloma. Leukemia research. 2015;39(9):971-5.

25. Sharma R, Mody N, Kushwah V, Jain S, Vyas S. C-Type lectin receptor(s)-targeted nanoliposomes: an intelligent approach for effective cancer immunotherapy. Nanomedicine (London England). 2017;12(16):1945-59.

26. Vitor M, Bergami-Santos P, Zômpero R, Cruz K, Pinho M, Barbuto J. et al. Cationic liposomes produced via ethanol injection method for dendritic cell therapy. J Liposome Res. 2017;27(4):249 63. 
27. Takahashi N, Higashi K, Ueda K, Yamamoto K, Moribe K. Determination of Nonspherical Morphology of Doxorubicin-Loaded Liposomes by Atomic Force Microscopy. Journal of pharmaceutical sciences. 2018;107(2):717 - 26.

28. Yamamoto E, Miyazaki S, Aoyama C, Kato M. A simple and rapid measurement method of encapsulation efficiency of doxorubicin loaded liposomes by direct injection of the liposomal suspension to liquid chromatography. International journal of pharmaceutics. 2018;536(1):21 - 8.

29. Jin S, He D, Luo D, Wang Y, Yu M, Guan B. et al. A Biomimetic Hierarchical Nanointerface Orchestrates Macrophage Polarization and Mesenchymal Stem Cell Recruitment To Promote Endogenous Bone Regeneration. ACS Nano. 2019;13(6):6581-95.

30. Mielczarek L, Krug P, Mazur M, Milczarek M, Chilmonczyk Z, Wiktorska K. In the triple-negative breast cancer MDA-MB-231 cell line, sulforaphane enhances the intracellular accumulation and anticancer action of doxorubicin encapsulated in liposomes. International journal of pharmaceutics. 2019;558:311-8.

31. Wen X, Li J, Cai D, Yue L, Wang Q, Zhou L. et al. Anticancer Efficacy of Targeted Shikonin Liposomes Modified with RGD in Breast Cancer Cells. Molecules (Basel, Switzerland). 2018;23(2).

32. Chakraborty P, Dash S, Dalpati N, Kumar P, Jain D, Sarangi P. A C-terminal fragment of adhesion protein fibulin-7 inhibits growth of murine breast tumor by regulating macrophage reprogramming. FEBS J. 2021;288(3):803 - 17.

33. Massi D, Marconi C, Franchi A, Bianchini F, Paglierani M, Ketabchi S. et al. Arginine metabolism in tumor-associated macrophages in cutaneous malignant melanoma: evidence from human and experimental tumors. Human pathology. 2007;38(10):1516-25.

34. Song M, Wang J, Lei J, Peng G, Zhang W, Zhang Y. et al. Preparation and Evaluation of Liposomes Co-Loaded with Doxorubicin, Phospholipase D Inhibitor 5-Fluoro-2-Indolyl Deschlorohalopemide (FIPI) and D-Alpha Tocopheryl Acid Succinate (a-TOS) for Anti-Metastasis. Nanoscale Res Lett. 2019;14(1):138.

35. Ottewell P, Mönkkönen H, Jones M, Lefley D, Coleman R, Holen I. Antitumor effects of doxorubicin followed by zoledronic acid in a mouse model of breast cancer. J Natl Cancer Inst. 2008;100(16):1167-78.

36. Miranda D, Huang H, Kang H, Zhan Y, Wang D, Zhou Y. et al. In VivoHighly-Soluble Cyanine Jaggregates Entrapped by Liposomes for Optical Imaging around $930 \mathrm{~nm}$. Theranostics. 2019;9(2):381 - 90.

37. Zhao M, Li J, Liu J, Xu M, Ji H, Wu S. et al. Charge-switchable nanoparticles enhance Cancer immunotherapy based on mitochondrial dynamic regulation and immunogenic cell death induction. Journal of controlled release: official journal of the Controlled Release Society. 2021;335:320 - 32.

38. Meng Z, Zhang R, Wang Y, Zhu G, Jin T, Li C. et al. miR-200c/PAl-2 promotes the progression of triple negative breast cancer via M1/M2 polarization induction of macrophage. Int Immunopharmacol. 2020;81:106028. 
39. Tanaka N, Takeda K, Kawasaki Y, Yamane K, Teruya Y, Kodani M. et al. Early Intensive Nutrition Intervention with Dietary Counseling and Oral Nutrition Supplement Prevents Weight Loss in Patients with Advanced Lung Cancer Receiving Chemotherapy: A Clinical Prospective Study. Yonago acta medica. 2018;61(4):204 - 12.

40. Wallace PW, Conrad C, Brückmann S, Pang Y, Caleiras E, Murakami M. et al. Metabolomics, machine learning and immunohistochemistry to predict succinate dehydrogenase mutational status in phaeochromocytomas and paragangliomas. J Pathol. 2020.

41. Yang Q, Guo N, Zhou Y, Chen J, Wei Q, Han M. The role of tumor-associated macrophages (TAMs) in tumor progression and relevant advance in targeted therapy. Acta pharmaceutica Sinica B. 2020;10(11):2156-70.

\section{Figures}
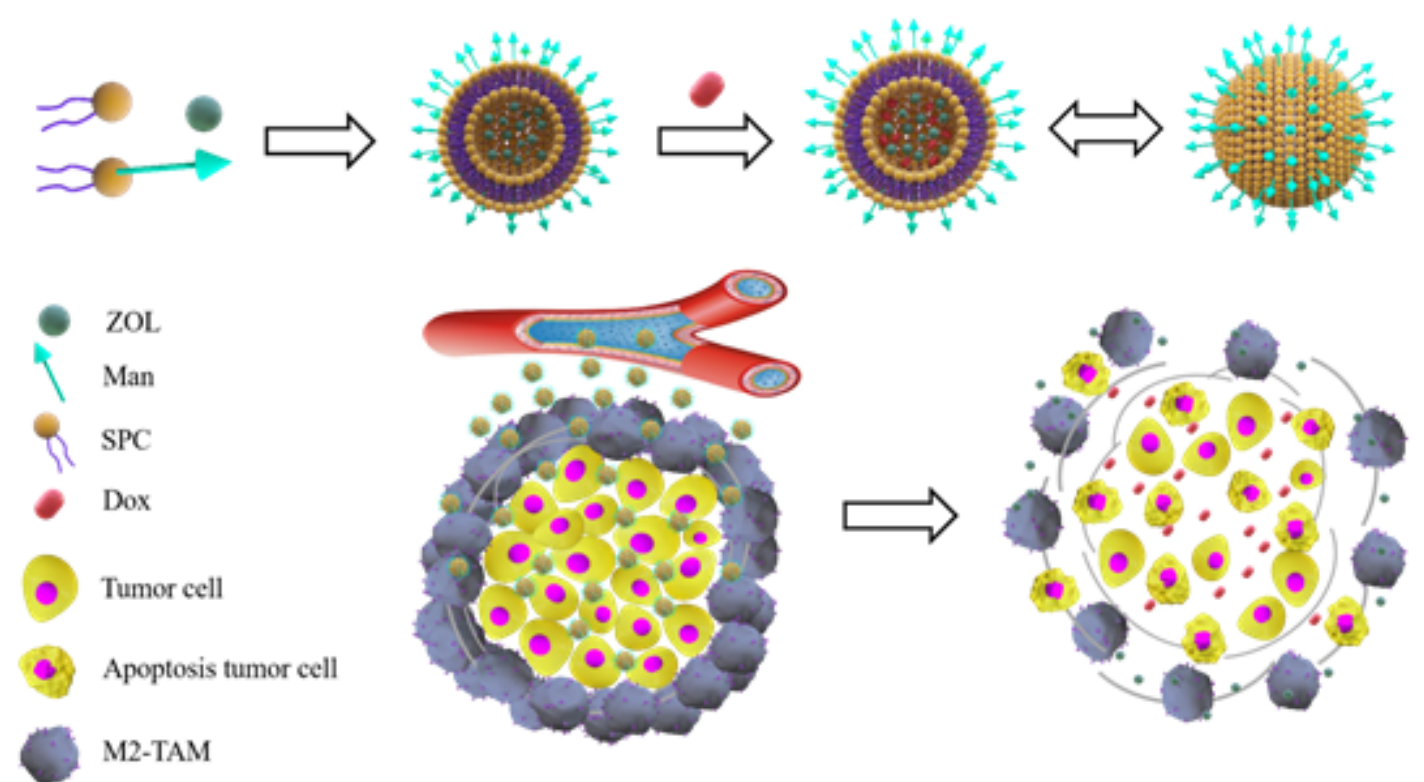

\section{Figure 1}

Schematic illustration for the preparation and mechanism of Man-LP@ZOL/DOX. 


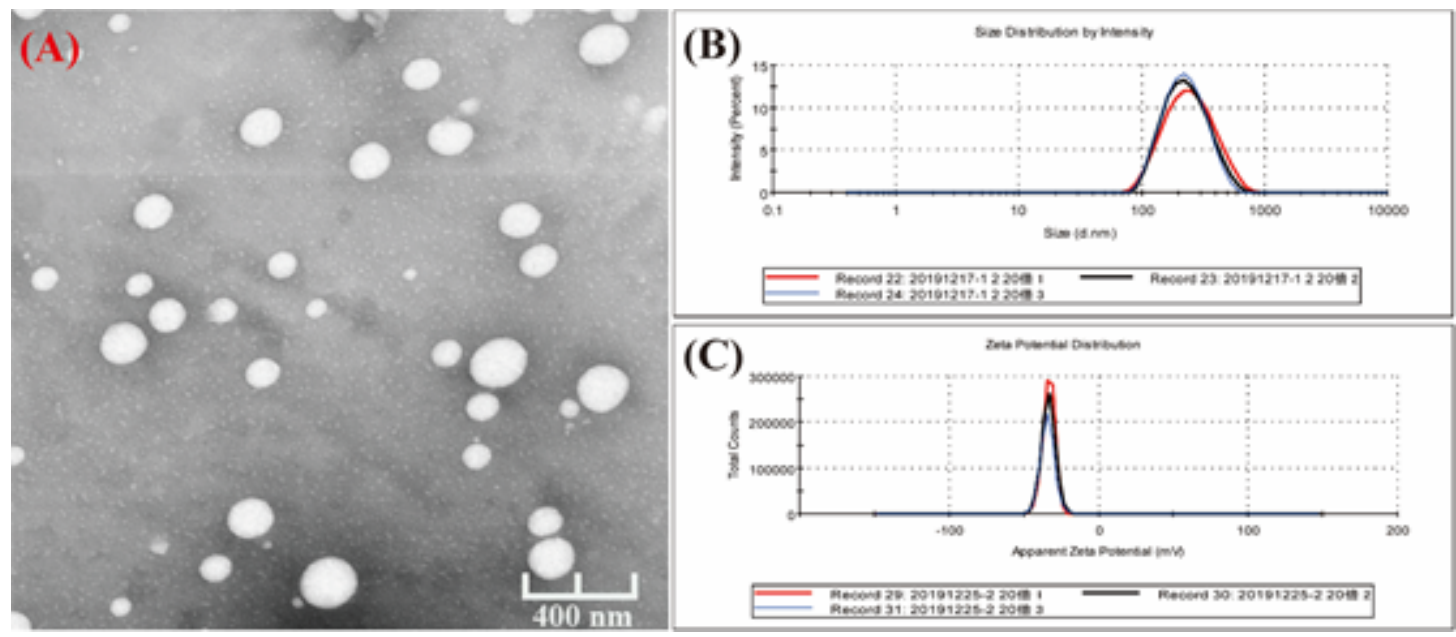

Figure 2

TEM images (A), size (B), and Zeta-potential (C) of Man-LP.
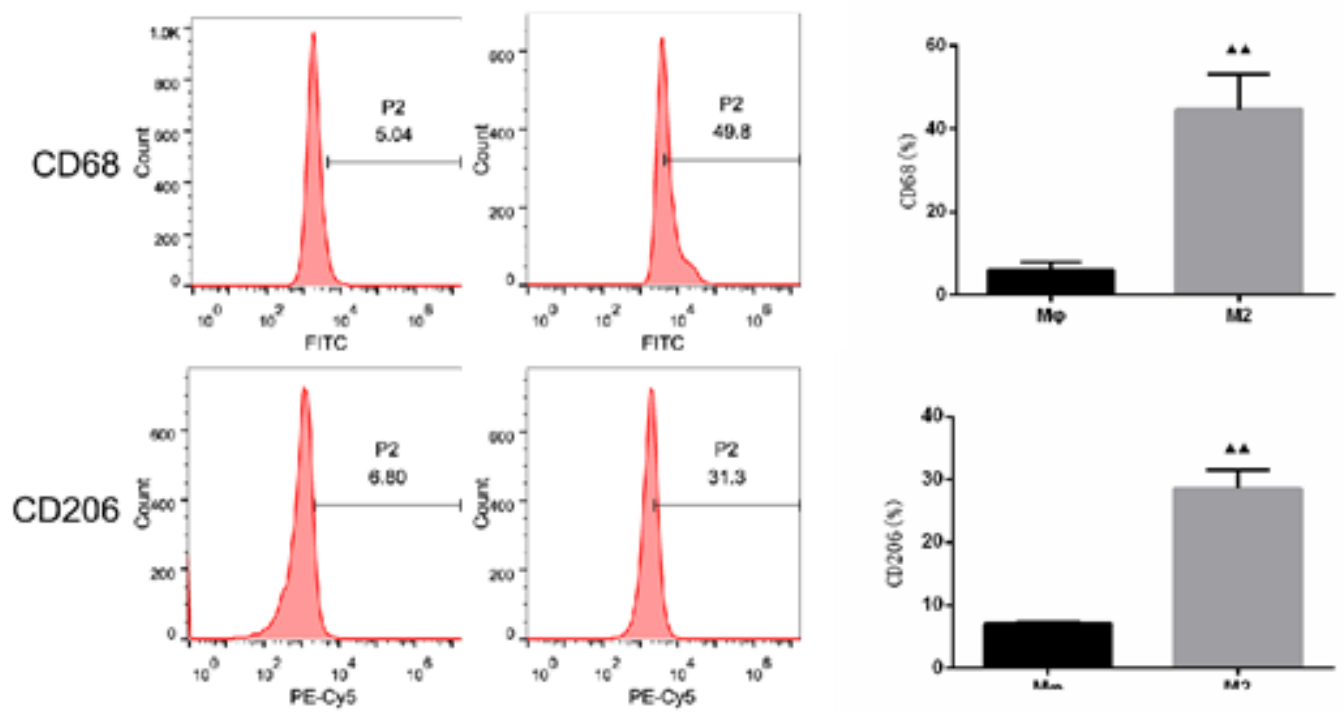

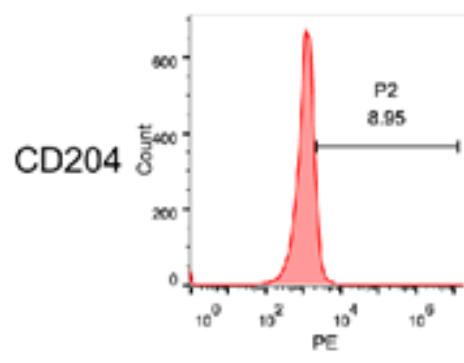

$\mathrm{M \varphi}$

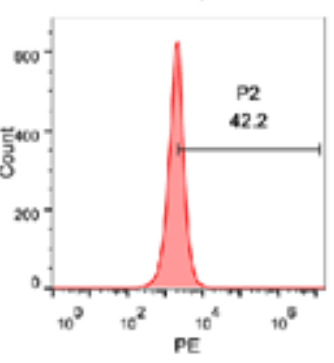

M2

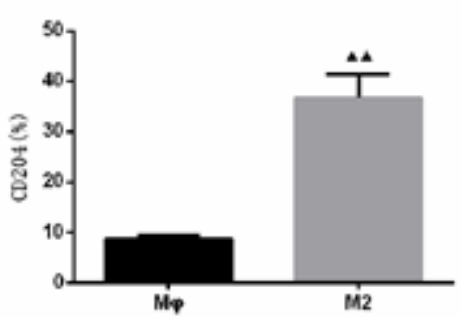

\section{Figure 3}

The expression of biomarkers (CD68, CD206, and CD204) in M2-TAMs before and after induction detected by flow cytometry $(n=3)$. $\mathbf{\Delta} \mathbf{\Delta} P<0.01$ vs. $M \varphi$ group. 


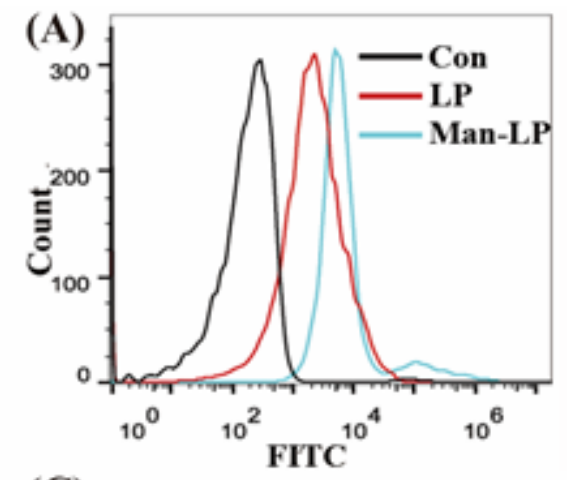

(C) Con

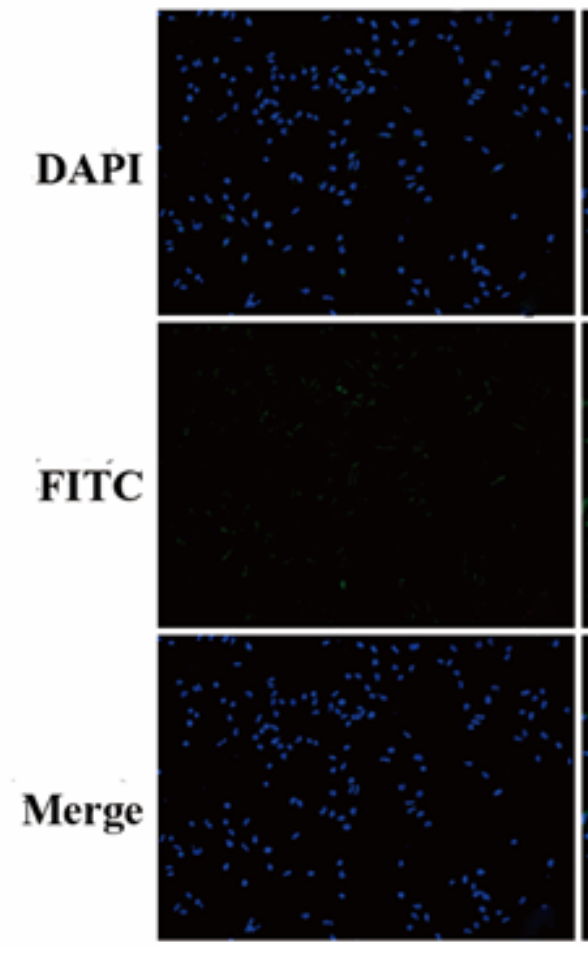

(B)

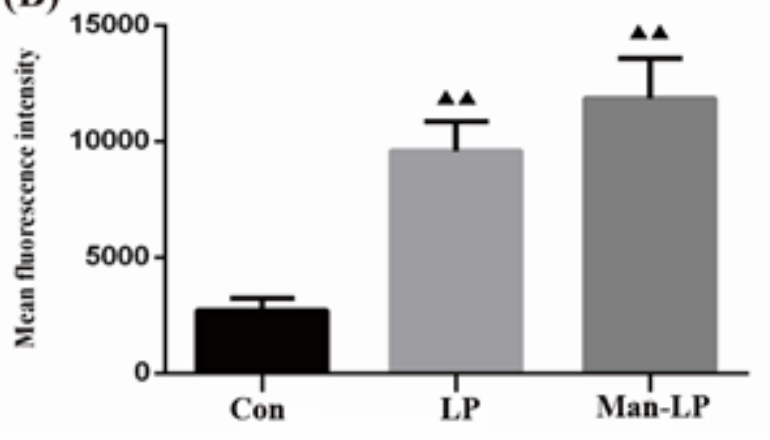

LP

Man-LP
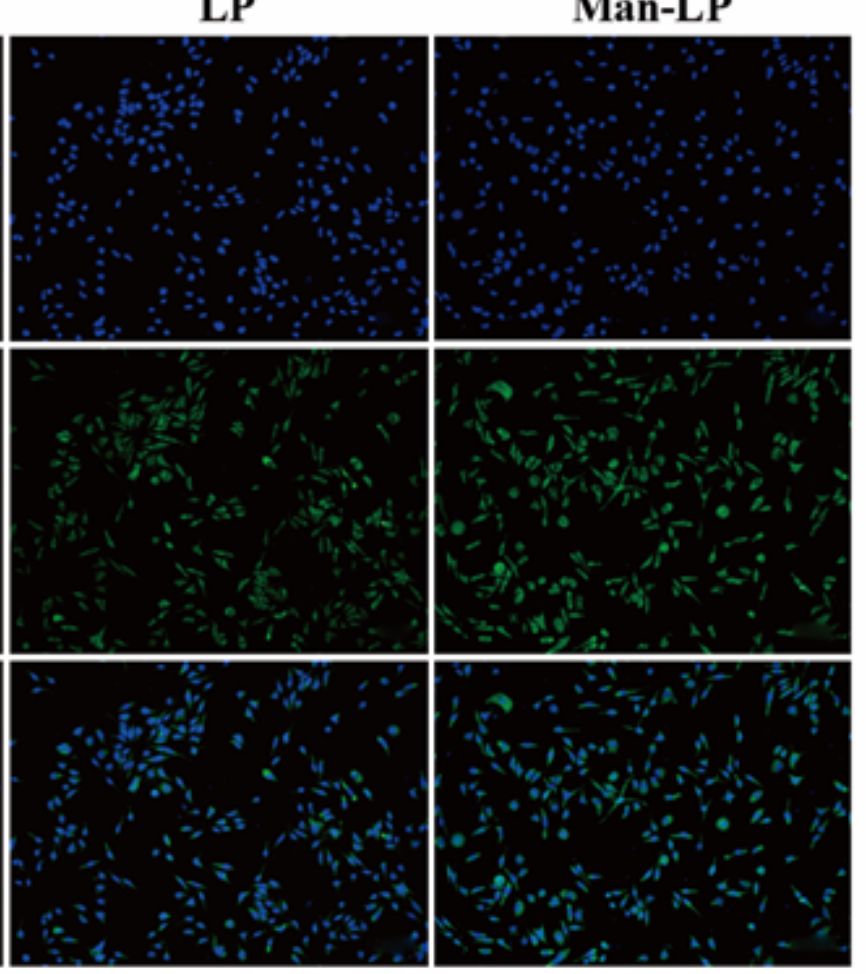

\section{Figure 4}

Flow cytometry profiles and mean fluorescence intensity of M2-TAMs incubated with blank serum-free culture medium, FITC-labeled LP, or FITC-labeled Man-LP (containing $3 \mu \mathrm{mol} / L$ FITC, $n=3$ ). $\mathbf{\Delta} \mathbf{\Delta} P<0.01$ vs. control group. Confocal images (C) of M2-TAMs incubation for $4 \mathrm{~h}$ with blank serum-free culture medium, FITC-labeled LP, or FITC-labeled Man-LP (containing $3 \mu \mathrm{mol} / \mathrm{L}$ FITC). For each group, the cell nucleus was stained with Hoechst 33342 (blue). Scale bar=50 $\mu \mathrm{m}$.
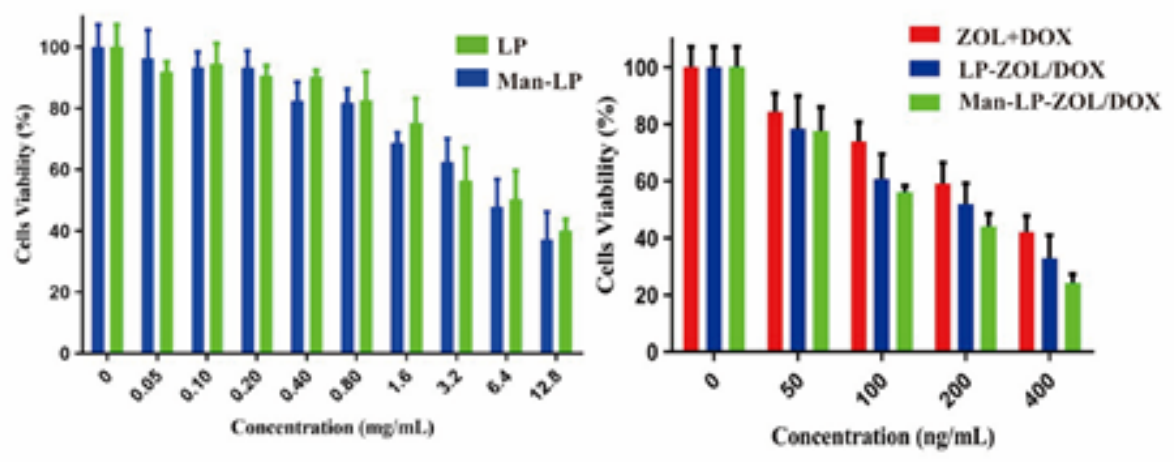


\section{Figure 5}

MTT assay of MDA-MB-231 treated with medium containing LP and Man-LP at concentrations ranging from 0.05 to $12.8 \mathrm{mg} / \mathrm{mL}$ for $48 \mathrm{~h}(\mathrm{n}=6)$. The viability of MDA-MB-231 treated with medium containing DOX+ZOL, LP@ZOL+DOX, and Man-LP@ZOL+DOX during a certain concentration range $(n=6)$.

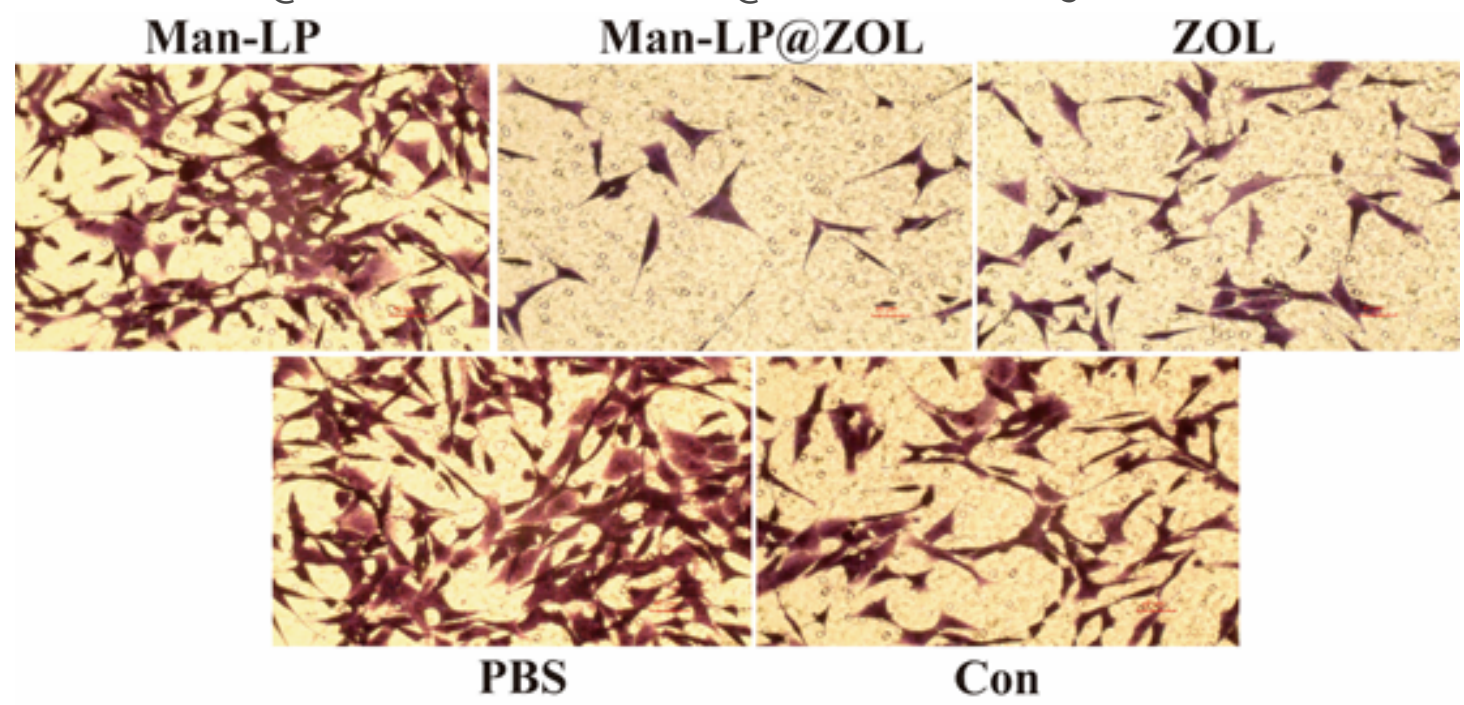

Figure 6

The pictures of MDA-MB-231 cells in co-cultivation system with M2-TAM that have invaded to the lower layer stained with $0.1 \%$ crystal violet after being treated with PBS, ZOL, Man-LP, and Man-LP@ZOL $(n=3)$. The control group was not seeded with M2-TAMs at the below transwell plate. 
(A)
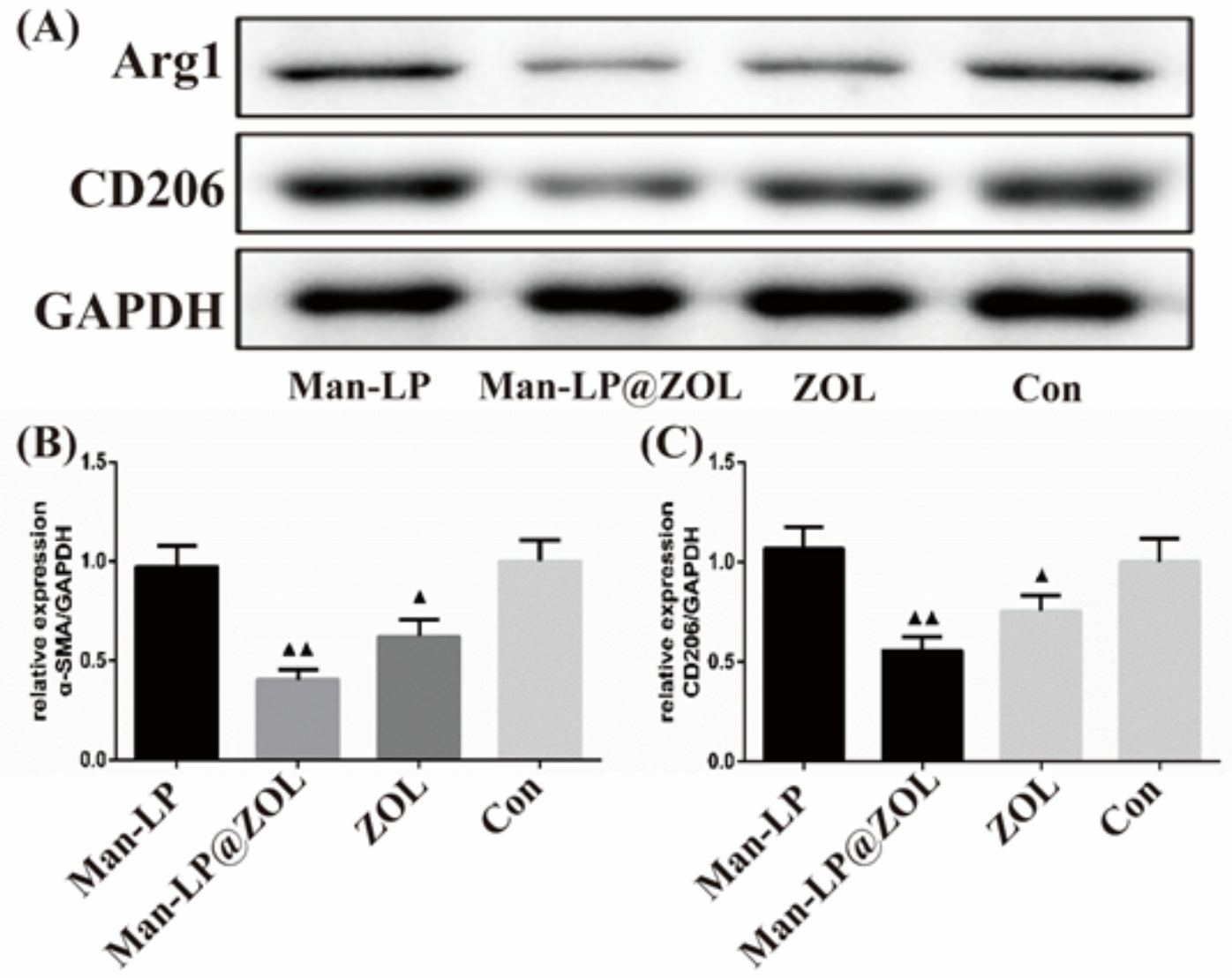

Figure 7

Western blot analysis (A) for Arg1 and CD206 in M2-TAM treated with PBS, ZOL, Man-LP, and ManLP@ZOL $(n=3)$. The semiquantitative results of Western blot for Arg1 (B) and CD206 (C). $\triangle P<0.05$, $\Delta \mathbf{\Delta} P<0.01$ vs. control group.
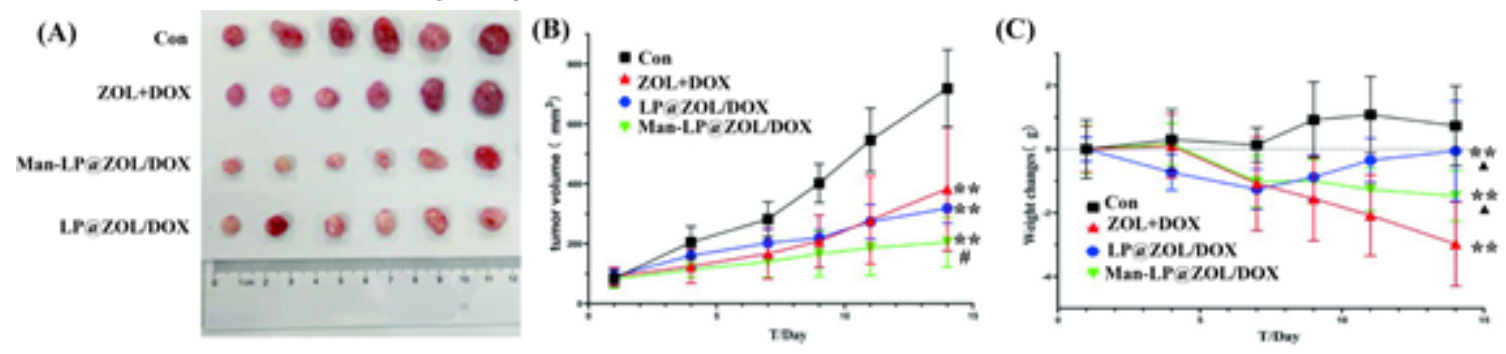

Figure 8

The tumor photographs $(A)$ on day $14(n=6)$. Tumor volume curves $(B)$ after intravenous injection of PBS, ZOL+DOX, LP@ZOL/DOX, or Man-LP@ZOL/DOX. **P<0.01 vs. control group, \#P<0.05 vs. LP@ZOL/DOX group. Mean weight changes $(C)$ of mice in different groups during treatment $(n=6)$. ${ }^{*} P<0.01$ vs. control group, $\Delta \mathrm{P}<0.05$ vs. ZOL+DOX group. 

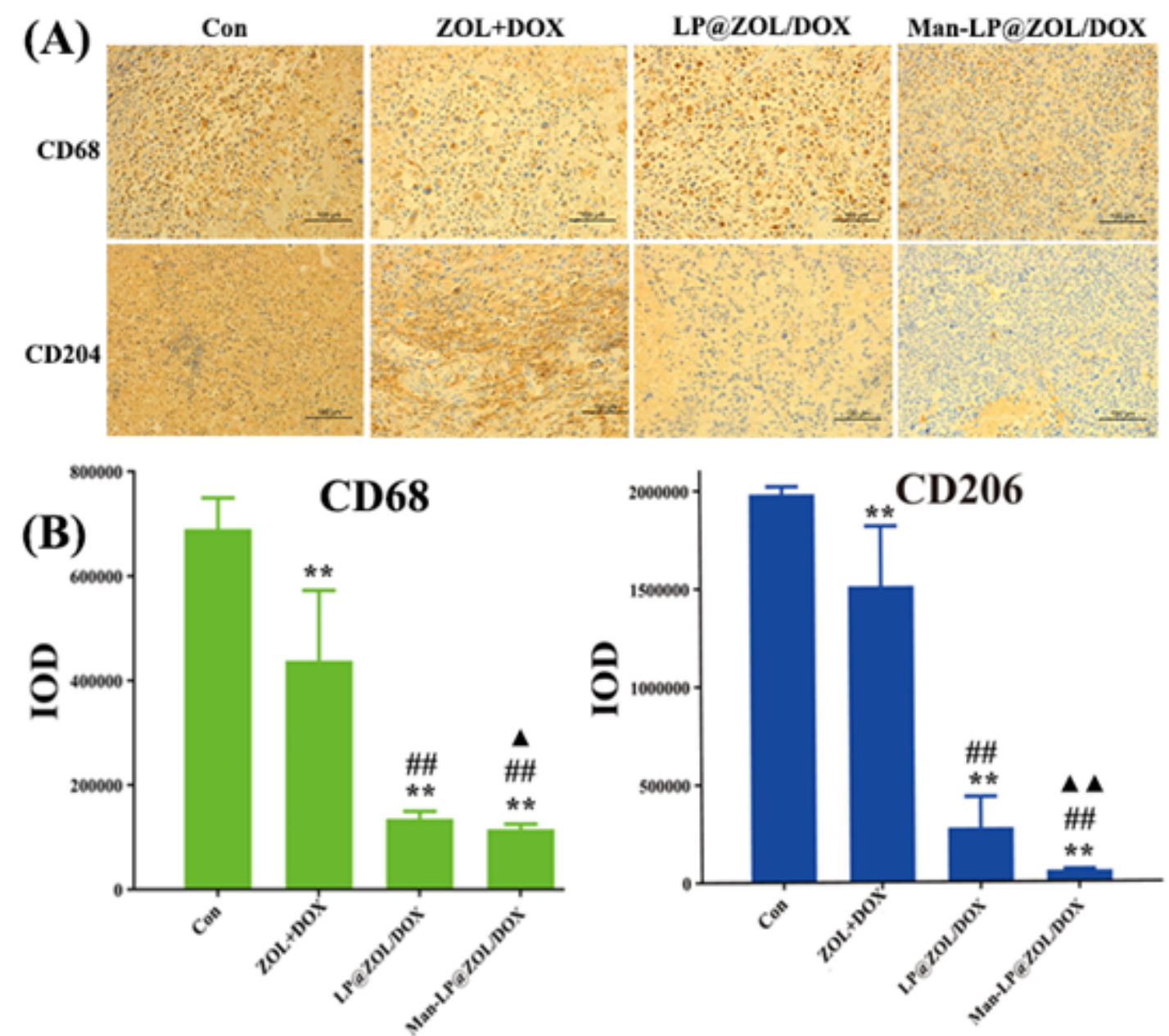

Figure 9

Immunohistochemistry staining images (A) and IOD (B) of CD68 and CD208 $(n=3$, scale bar $=100 \mu \mathrm{m})$. **P<0.01 vs. control group, \#\#P<0.01 vs. ZOL+DOX group, $\Delta \mathbf{\Delta} P<0.01$ and $\mathbf{\Delta} P<0.05$ vs. LP@ZOL/DOX group.

\section{Supplementary Files}

This is a list of supplementary files associated with this preprint. Click to download.

- floatimage1.png 